\title{
Focus on patients, the rest will follow, says new CMA pres
}

- Cite as: CMAJ 2017 September 11;189:E1165-6. doi: 10.1503/cmaj.1095481

Posted on cmajnews.com on Aug. 22, 2017.

anada's health system should serve the interests and needs of patients first and foremost, says incoming Canadian Medical Association (CMA) President Dr. Laurent Marcoux.

"Despite the challenges we're facing, and the need to adapt the way we practice, our professionalism will always be defined as total commitment to our patients," Marcoux said in his inaugural address to CMA General Council. Technology is opening up new frontiers in medicine, but more importantly, "new modes of communication to allow each and every one of us to act and advocate on behalf of our patients," he said.

Innovation and advocacy for patients will be central concerns of Marcoux's term as CMA president. "We're better positioned than anyone to understand their needs and the most appropriate ways to meet their expectations," he said.

Since graduating from the Université Laval in Quebec City in 1973, Marcoux has worked in many areas of medicine, with a focus on improving access to care. In 1976, he founded the Centre médical Saint-Denis, a rural primary and secondary care clinic where he practised family medicine. He also practised general medicine in a short-term institution, provided house calls for seniors in his community, and served as president of the council of physicians, dentists and pharmacists of the Centre hospitalier Honoré-Mercier in Saint-Hyacinthe.

Long before "patient-centred" became a buzzword in medicine, Marcoux recognized that his colleagues' greatest unhappiness stemmed from systems that got in the way of serving their patients. "If we have to struggle with the health care system that doesn't provide the patient's

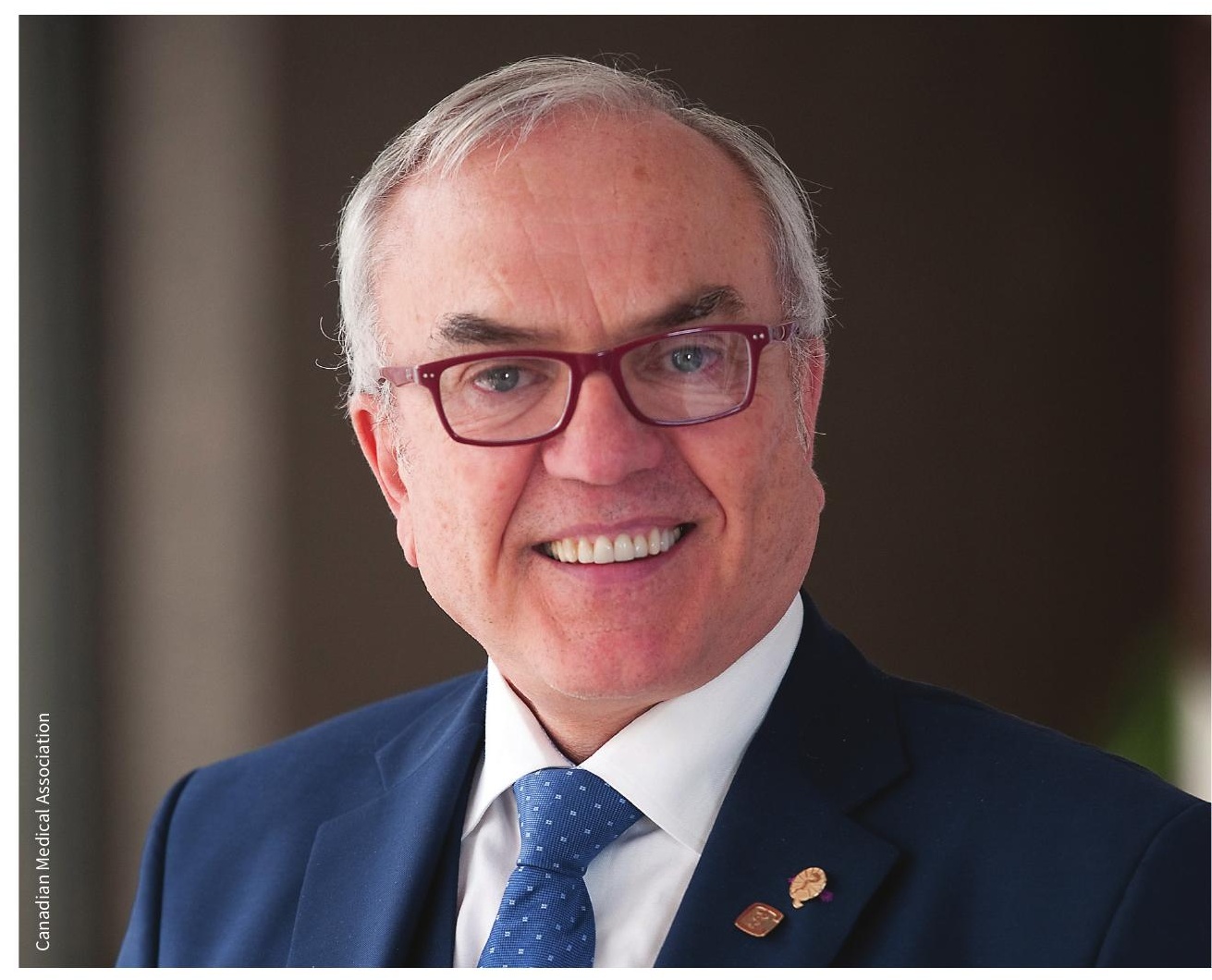

Canadian Medical Association President Dr. Laurent Marcoux says that serving patients first serves physicians, too.

need, that's a big disappointment for a doctor and it can make him angry and frustrated," he told CMAJ.

Marcoux's interest in health reform led him to complete a master's degree in health administration at the Universite de Montréal in 2000, and then to head the regional general medicine department in Montérégie, the second largest region in Quebec. During this period, Marcoux also served as director of professional services and medical affairs at the Centre de santé et services sociaux Jardins-Roussillon in Châteauguay, as well as a member of several provincial committees.
His experiences convinced him that the hospital-centric model of health care established under medicare five decades ago is "no longer relevant," particularly for an aging population. "We have to change the organization to avoid what is not necessary and bring the care when and where it is needed," Marcoux said.

In the case of seniors, that means bringing care to the home. "They don't want to go every time they need some care to the emergency room ... but they don't have any other choice."

Marcoux cited the example of requiring patients with diabetes in rural areas to 
travel long distances to Montréal for annual eye checkups. Huge costs for patients and the system were avoided simply by training health workers to take photographs of patients' retinas that could be assessed remotely, he said.

Not only are Canadians aging, but their expectations of physicians are changing, too. "The mindset is different than before, and we are the ones who serve the patients," Marcoux explained. "We have to put the interests and the needs of our patients as a whole before our own."

Although the profession often pays lip service to this ideal, turning rhetoric into reality will require a substantial dose of humility, he says. "We have to be able to stop bringing our solution in our head ... and listen to the frustration of our patients and not say they're just spoiled, they want more and more."

This is particularly true when it comes to Indigenous patients, he says. From 2012 to 2016, Marcoux was director of medical affairs and services of the Cree Board of Health and Social Services of James Bay. "They understand what's better for them ... we don't have to impose our solution."

He also urged flexibility in dealings with government. "We have to work with them because they have some constraints and some points of view we have to con- sider," he said. "We are not the master of all; we have to consider the reality of a country - economically, socially."

For Marcoux, this isn't at odds with strong advocacy for the medical profession. He was president of the Quebec Medical Association from 2014 to 2015, and one of two Quebec representatives on the CMA board from 2011 to 2016.

"We must not be afraid to push for the change. We have to be bolder. We have to be courageous," he said. "It's our need to serve the population but in the manner we are happy, so that we don't feel we are pushed by the system."

Lauren Vogel, CMAJ 